Jpn. J. Human Genet. 29, 45-50, 1984

\title{
EFFECTS OF PARENTAL AGE AND BIRTH ORDER IN MOTOR NEURON DISEASE
}

\author{
Kiyotaro Kondo ${ }^{1}$ and Keiko FuJIKI \\ Department of Neurology, Tokyo Metropolitan Institute for Neurosciences, \\ 2.6 Musashidai, Fuchu, Tokyo 183, Japan
}

\begin{abstract}
Summary Effects of the parental age, birth order, sib size and the interval between the birth of a case and of his immediately senior sib were evaluated in 309 cases of motor neuron disease whether they are related with subsequent development of the disease. The spouses were used as the controls. The results were negative.
\end{abstract}

\section{INTRODUCTION}

Although the cause of motor neuron disease (MND) is still obscure, indirect evidences suggested that a complex interplay of genetic and environmental factors underlies its pathogenesis. While changing long-term trends and association with some factors such as mechanical injuries or heavy metal exposures suggested role of exogenous agents, they are by no means acceptable as single causes of the disease (Kondo and Tsubaki, 1977, 1981; Yase, 1977). Regarding host factors, weak familial aggregation is observed, but no Mendelian hypothesis adequately explained the family pattern, and association with inherited variants such as the major histocompatibility antigens was not unequivocally established (Emery and Holloway, 1982; Antel et al., 1982). The present study attempted to find a clue whether intrauterine factors predispose to subsequent development of MND by evaluating effects of the birth order and the age of parents at the birth of the victims on the risks to the disease.

\section{MATERIALS AND METHODS}

Family information in 309 cases of MND was collected from their Koseki and analyzed along with the control data.

The index cases. As already reported; 1) 3,255 death certificates with 10 codes in the 8th Revision of the International Classification of Diseases including 356, or MND and muscular atrophies, were retrieved out of 700,438 deaths in Japan in 1965,

Received February 10, 1984

${ }^{1}$ To whom correspondence and reprint requests should be addressed. 
2) 916 were preliminarily selected rejecting definitely unapplicable cases, 3) 51 times of clinical information were collected from the certifying physicians, 4) on the other hand, 137 cases were selected from the Annals of Pathological Autopsies in Japan which excerpted nearly all autopsies in Japan, for which the same clinical information was collected (Kondo and Tsubaki, 1977). Clinical diagnosis was correct in $98 \%$ of the autopsied cases clinically diagnosed as MND. These surveys, which were made as a preliminary step for epidemiological studies, yielded 384 definite cases including 299 amyotrophic lateral sclerosis (ALS), 10 progressive bulbar paralysis (PBP) and 75 spinal progressive muscular atrophies (SPMA), which were used as the index cases in the present study.

Family information. For the index cases and their spouses, dates and places of the birth of the parents, brothers and sisters were collected through the Koseki. Koseki is a legally enforced family registry for the Japanese nationals in which individual vital information is recorded, updated and filed by the local administrative offices throughout the country (Ohkura, 1960). In Japan, legal right is given at birth except special situations, but deaths occurring immediately after the birth may be unreported to the administrators in very rare cases in former days, though such failure was unlawful.

Following variables were calculated based on the family information for each case and control; 1) year of birth, 2) sex, 3) and 4) age of the father and the mother respectively, at the birth of a case or a control, 5) number of siblings including a case or a control, 6) birth order, and 7) interval between the birth of a case or a control and that of an immediately senior sib. Controls of male cases were husbands of female cases, those of female cases being wives of male cases.

Errors are negligible in 1)-4), but due to rare underreportings of neonatal death, 5) and 6) may be slightly underestimated and therefore, 7) may be slightly overestimated to an equal extent in the cases and the controls, however. Births were not controlled and artificial abortion was severely punished when the vast majority of cases and the controls were born. The present materials, therefore, represent natural reproduction patterns in Japan in these days.

Analyses. Males and females were separately analyzed. Years and areas of the birth were compared with between cases and controls and their parents in order to know whether they are comparable. The third to the seventh variables were then evaluated.

\section{RESULTS}

Adequate information was available in 197 and 101 male cases and controls, respectively, as well as in 112 and 143 female cases and controls.

Comparability between cases and the controls. In males, the years of birth were ranged between 1889-1950 in the cases, and between 1883-1946 in the controls averaging $1,909.8$ and $1,905.6$ respectively, which disclosed no difference $(0.05<p<0.1)$. In females, they were during $1882-1941$ and 1890-1939, both averaging 1,911.3, again 
with no difference. Areas of birth did not differ between the cases and the controls, between the mothers and fathers of the cases or the controls, although no data is shown. Behaviors of reproduction may differ from time to time and from place to place, but these results suggested cases and controls were reasonably comparable.

Parental age. Tables 1 and 2 show ages of the fathers and mothers at the birth of the cases or controls. In all age groups of the parents, number of the cases did not differ significantly from the expected number based on the number of the controls in either sex, as revealed by their chi-squares. Mean parental ages were same, as indicated by their $t$-values shown in the tables.

Table 1. Paternal age at the birth of the cases and controls.

\begin{tabular}{|c|c|c|c|c|c|c|c|c|c|c|c|}
\hline \multicolumn{2}{|c|}{ Age } & -19 & $20-24$ & $25-29$ & $30-34$ & $35-39$ & $40-44$ & $45-49$ & 50 & Average & Total \\
\hline \multirow{4}{*}{ Males } & Cases & 2 & 10 & 47 & 46 & 36 & 30 & 12 & 5 & $34.0 \pm 7.4$ & 188 \\
\hline & Controls & 3 & 13 & 17 & 24 & 16 & 5 & 5 & 6 & $32.7 \pm 8.9$ & 89 \\
\hline & $E$ & 3.4 & 15.6 & 43.4 & 47.5 & 35.3 & 23.8 & 11.5 & 7.5 & & 188.0 \\
\hline & $x^{2}$ & 0.58 & 2.01 & 0.30 & 0.05 & 0.01 & 1.62 & 0.02 & 0.83 & & 5.42 \\
\hline \multirow{4}{*}{ Females } & Cases & - & 14 & 22 & 29 & 22 & 15 & 3 & - & $32.5 \pm 6.7$ & 105 \\
\hline & Controls & - & 14 & 30 & 36 & 30 & 17 & 7 & 2 & $33.3 \pm 7.0$ & 136 \\
\hline & $\mathrm{E}$ & - & 12.2 & 22.7 & 28.3 & 22.7 & 13.9 & 4.4 & 0.9 & & 105.1 \\
\hline & $x^{2}$ & - & 0.27 & 0.02 & 0.02 & 0.02 & 0.09 & 0.45 & 0.9 & & 1.77 \\
\hline
\end{tabular}

Total is short of those of the cases or controls because information was unavailable in a few individuals. E is the expected number of the cases based on the paternal age distribution of the controls. Chi-square values were smaller than $\chi_{1}^{2}(0.05)=3.84$ for each value and $\chi_{7}{ }^{2}(0.05)=14.07$ for total value. $t$-values for the average were 1.19 in males and 0.92 in females $\left(<t_{240}(0.05)=1.97\right)$.

Table 2. Maternal age at the birth of the cases and controls.

\begin{tabular}{|c|c|c|c|c|c|c|c|c|c|}
\hline \multicolumn{2}{|c|}{ Age } & -19 & $20-24$ & $25-29$ & $30-34$ & $35-39$ & $40-$ & Average & Total \\
\hline \multirow{4}{*}{ Males } & Cases & 6 & 53 & 46 & 31 & 27 & 25 & $29.7 \pm 7.2$ & 188 \\
\hline & Controls & 7 & 31 & 19 & 20 & 14 & 8 & $28.5 \pm 7.3$ & 99 \\
\hline & $E$ & 8.5 & 55.0 & 42.6 & 33.4 & 26.9 & 21.6 & & 188.0 \\
\hline & $x^{2}$ & 0.74 & 0.07 & 0.27 & 0.17 & 0.00 & 0.54 & & 1.79 \\
\hline \multirow{4}{*}{ Females } & Cases & 7 & 26 & 35 & 21 & 17 & 4 & $28.3 \pm 6.2$ & 110 \\
\hline & Controls & 8 & 31 & 34 & 35 & 24 & 8 & $29.0 \pm 6.5$ & 140 \\
\hline & $\mathrm{E}$ & 6.6 & 25.1 & 30.4 & 24.6 & 18.0 & 5.3 & & 110.0 \\
\hline & $x^{2}$ & 0.02 & 0.03 & 0.70 & 0.53 & 0.06 & 0.32 & & 1.66 \\
\hline
\end{tabular}

Chi-square values were smaller than $\chi_{1}{ }^{2}(0.05)=3.84$ for the each value and $\chi_{5}{ }^{2}(0.05)=11.07$ for total value. $t$-values for the average were 1.38 in males and 0.92 in females $\left(<t_{240}(0.05)=1.97\right)$. 
Birth order. Table 3 summarizes the results. In all birth order groups, number of the cases did not differ from the expected number in either sex. Average birth orders were identical, as shown by their t-values. The first and the pooled subsequent birth orders were compared disclosing that the primogeniture cases were deficient in the males.

Sib size. Sib size may differ from time to time, but comparisons by the year of birth showed no difference and the data were pooled. Table 4 represents distributions of the sib size with the cases or controls inclusive. No difference was observed in each sib size group in either sex, as well as in the averages.

Birth interval. The data were summarized in Table 5, which disclosed no difference in each birth interval group. The average interval in the males was significantly greater than that of the controls, however.

Tabie 3. Birth order of the cases and controls.

\begin{tabular}{clccccccc}
\hline \multicolumn{2}{c}{ Birth order } & 1 & 2 & 3 & $4+5$ & $6-$ & Average & Total \\
\hline \multirow{4}{*}{ Males } & Cases & 43 & 36 & 32 & 51 & 29 & $3.26 \pm 1.87$ & 191 \\
& Controls & 35 & 15 & 14 & 15 & 18 & $2.99 \pm 2.09$ & 97 \\
\cline { 2 - 9 } & $\mathrm{E}$ & 51.7 & 33.8 & 30.5 & 43.8 & 31.2 & & 191.0 \\
& $\chi^{2}$ & 1.46 & 0.14 & 0.07 & 1.18 & 0.16 & & 3.01 \\
\hline \multirow{3}{*}{ Females } & Cases & 32 & 22 & 16 & 18 & 21 & $3.16 \pm 2.10$ & 109 \\
& Controls & 36 & 27 & 19 & 31 & 28 & $3.28 \pm 2.01$ & 141 \\
\cline { 2 - 9 } & $\mathrm{E}$ & 29.6 & 21.4 & 15.3 & 21.4 & 21.4 & & 109.1 \\
& $\chi^{2}$ & 0.19 & 0.02 & 0.03 & 0.54 & 0.01 & & 0.79 \\
\hline
\end{tabular}

Chi-square values were smaller than $\gamma_{I}{ }^{2}(0.05)=3.84$ for each value and $\chi_{4}{ }^{2}(0.05)=9.49$ for total value. $t$-values for the average were 1.06 in males and 0.37 in females $\left(<t_{240}(0.05)=1.97\right)$.

Table 4. Sib size of the cases and controls.

\begin{tabular}{clccccccc}
\hline \multicolumn{2}{c}{ Sib size } & 1 & 2 & 3 & $4+5$ & $6-$ & Average & Total \\
\hline \multirow{4}{*}{ Males } & Cases & 11 & 13 & 18 & 53 & 96 & $5.6 \pm 2.6$ & 191 \\
& Controls & 13 & 21 & 27 & 75 & 151 & $5.9 \pm 2.6$ & 287 \\
\cline { 2 - 8 } & $\mathrm{E}$ & 8.7 & 14.0 & 18.0 & 49.9 & 100.5 & 191.1 \\
& $\chi^{2}$ & 0.61 & 0.07 & 0.00 & 0.19 & 0.20 & 1.07 \\
\multirow{5}{*}{ Females } & Cases & 5 & 7 & 10 & 24 & 63 & $6.0 \pm 2.6$ & 109 \\
& Controls & 13 & 14 & 23 & 56 & 144 & $5.9 \pm 2.5$ & 250 \\
\cline { 2 - 9 } & $\mathrm{E}$ & 5.7 & 6.1 & 10.0 & 24.4 & 62.8 & & 109.0 \\
& $x^{2}$ & 0.09 & 0.13 & 0.00 & 0.01 & 0.00 & 0.23 \\
\hline
\end{tabular}

Chi-square values were smaller than $\chi_{1}{ }^{2}(0.05)=3.84$ for each value and $\chi_{4}^{2}(0.05)=9.45$ for total value. $\mathrm{t}$-values for the average were 1.02 in males and 0.58 in female $\left(<t_{\infty}(0.05)=1.96\right)$.

Jpn. I. Human Genet. 
Table 5. Birth interval of the cases and controls.

\begin{tabular}{|c|c|c|c|c|c|c|c|c|c|c|c|c|c|}
\hline \multicolumn{2}{|c|}{ Years } & -1 & -1.5 & -2.0 & -2.5 & -3.0 & -3.5 & -4.0 & -4.5 & -5.0 & $\begin{array}{c}\text { Over } \\
0.5\end{array}$ & Average & Total \\
\hline \multirow{4}{*}{ 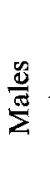 } & Cases & 4 & 5 & 9 & 28 & 26 & 14 & 16 & 5 & 7 & 27 & $3.6 \pm 1.4$ & 141 \\
\hline & Controls & 一 & 1 & 11 & 11 & 11 & 8 & 4 & 2 & 6 & 2 & $3.2 \pm 1.1$ & 56 \\
\hline & $\mathrm{E}$ & 2.9 & 4.3 & 14.3 & 27.9 & 25.8 & 15.8 & 14.3 & 5.0 & 9.3 & 21.5 & & 141.1 \\
\hline & $z^{2}$ & 0.45 & 0.12 & 1.97 & 0.00 & 0.00 & 0.19 & 0.20 & 0.20 & 0.57 & 1.42 & & 5.12 \\
\hline \multirow{4}{*}{ 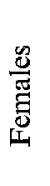 } & Cases & 3 & 4 & 9 & 24 & 15 & 4 & 2 & 4 & - & 8 & $3.0 \pm 1.2$ & 73 \\
\hline & Controls & 一 & 6 & 12 & 17 & 21 & 10 & 10 & 5 & 3 & 12 & $3.3 \pm 1.3$ & 96 \\
\hline & $\mathbf{E}$ & 1.3 & 4.3 & 9.1 & 17.7 & 15.6 & 6.1 & 5.2 & 3.9 & 1.3 & 8.6 & & 73.1 \\
\hline & $\chi^{2}$ & 2.22 & 0.02 & 0.00 & 2.23 & 0.02 & 0.69 & 1.95 & 0.00 & 1.30 & 0.05 & & 8.48 \\
\hline
\end{tabular}

Chi-square values were smaller than $\chi_{1}^{2}(0.05)=3.84$ for each value and $\chi_{9}{ }^{2}(0.05)=16.92$ for total value. $t$-values for the average were 2.14 in male $\left(>t_{200}(0.05)=1.97\right)$ and 1.78 in female $\left(<t_{200}(0.05)=1.97\right)$.

\section{DISCUSSION}

In 309 cases of MND; parental age, birth order, sib size and birth interval showed no difference from the control groups which comprised their spouses. Few comparisons disclosed weak differences at the $5 \%$ level in one of the two sexes, but the overall results appeared negative.

In some diseases due to congenital or perinatal etiologies, these variables change according to their pathomechanisms. Elevated maternal age in Down's trisomy, for example, is conditioned by the fact that chromosomal nondisjunction increases as the ova age. No direct evidence indicated that congenital or perinatal factors are related with a risk to MND which usually manifest in the sixth or later decade of life, but such possibility remains valid, because, among other facts, neurons are fixed postmitotic cells. They are produced in early life, and connected with other neurons or target organs. They age as the host individual ages. This study attempted to identify a change in the parental age etc., as a feasible approach to know whether some process in the developing stage of the motor system is related with subsequent development of MND after a long incubation. The study failed to disclose positive findings, however.

This study was supported by a grant from the Intractable Diseases Division, Ministry of Health and Welfare, Japan.

\section{REFERENCES}

Antel, J.P., Noronha, A.B.C., Oger, J.J.-F., and Arnason, B.G.W. 1982. Immunology of amyotrophic lateral sclerosis. In Human Motor Neuron Diseases, Rowland, L.P., ed., Raven, New York, pp. 395-401. 
Emery, E.H.A., and Holloway, S. 1982. Familial motor neuron disease. In Human Motor Neuron Diseases, Rowland, L.P. ed., Raven, New York, pp. 139-45.

Kondo, K., and Tsubaki, T. 1977. Changing mortality patterns of motor neuron disease in Japan. J. Neurol. Sci. 32: 411-424.

Kondo, K., and Tsubaki, T. 1981. Case-control studies of motor neuron disease, association with mechanical injuries. Arch. Neurol. 38: 220-226.

Ohkura, K. 1960. Use of the family registration in the study of human genetics in Japan. Jpn. $J$. Human Genet. 5 : $61-98$.

Yase, Y. 1977. ALS in the Kii peninsula, one possible etiological hypothesis. In Amyotrophic Lateral Sclerosis, Tsubaki, T., ed., University of Tokyo Press, Tokyo, pp. 307-317. 